\title{
The Problem of College Drinking: Insights From a Developmental Perspective
}

\author{
John Schulenberg, Jennifer L. Maggs, Stephen W. Long, Kenneth J. Sher, Heather J. Gotham, John S. Baer, \\ Daniel R. Kivlahan, G. Alan Marlatt, and Robert A. Zucker
}

\begin{abstract}
This article represents the proceedings of a symposium at the 2000 RSA Meeting in Denver, Colorado. John Schulenberg and Jennifer L. Maggs were Organizers. Stephen W. Long was Chair and provided opening remarks. The presentations were: (1) I'm not a drunk, just a college student: Binge drinking during college as a developmental disturbance, by John Schulenberg; (2) Course of alcohol use disorders during college, by Kenneth J. Sher; (3) How do students experience alcohol and its effects? Positive versus negative expectancies and consequences, by Jennifer L. Maggs; and (4) Brief intervention in the context of developmental trends in college drinking, by G. Alan Marlatt. Critique and commentary were provided by Robert A. Zucker.

Key Words: Binge Drinking, College Drinking, Developmental Disturbance Model, Alcohol Use Disorders, Alcohol Expectancies, Brief Intervention, Developmental Course.
\end{abstract}

D URING HIGH SCHOOL, college bound students drink alcohol (and use other drugs) to a far lesser extent than do their noncollege bound classmates. Indeed, college plans during high school consistently have been found to correlate negatively and significantly with alcohol and other drug use. Nevertheless, this protective shield of college plans quickly wears thin as young people enter college. As shown in Fig. 1 (based on national panel data drawn from the Monitoring the Future project; O'Malley and Johnston, in press; Schulenberg and Maggs, in press), binge (or heavy episodic) drinking (i.e., 5 or more drinks in a row) escalates quickly for college students, and does not decline until the early 20s as they leave college. In contrast, for noncollege bound youth, binge drinking tends to reach its peak during high school and then decline thereafter. It is noteworthy that there is not a similar divergence between college and noncollege youth for cigarettes or illicit drugs.

From the Institute for Social Research (JS), Department of Psychology (JS, $R A Z)$, and Alcohol Research Center (RAZ), University of Michigan, Ann Arbor, Michigan; Division of Family Studies and Human Development (JLM), University of Arizona, Tucson, Arizona; National Institute on Alcohol Abuse and Alcoholism (SWL), Bethesda, Maryland; Department of Psychology (KJS), University of Missouri, Columbia, Missouri; St. Louis VAMC (HJG), St. Louis, Missouri; Department of Psychology (JSB, GAM), Department of Psychiatry (DRK), University of Washington, and the VA Puget Sound Health Care System (JSB, DRK), Seattle, Washington.

Received for publication October 4, 2000; accepted November 22, 2000.

Supported by Grants AA06324 (JS), R37AA7231 (KJS, HJG), R37AA05591 (JSB, DRK, GAM), and AA07065, AA12217 (RAZ) from the NIAAA; DA01411 (JS) from the National Institute on Drug Abuse, and the Alcoholic Beverage Medical Research Foundation (JLM).

Reprint requests: John Schulenberg, PhD, Institute for Social Research, University of Michigan, Ann Arbor, MI, 48106-1248; Fax: 734-936-0043; E-mail: schulenb@umich.edu

Copyright (C) 2001 by the Research Society on Alcoholism.

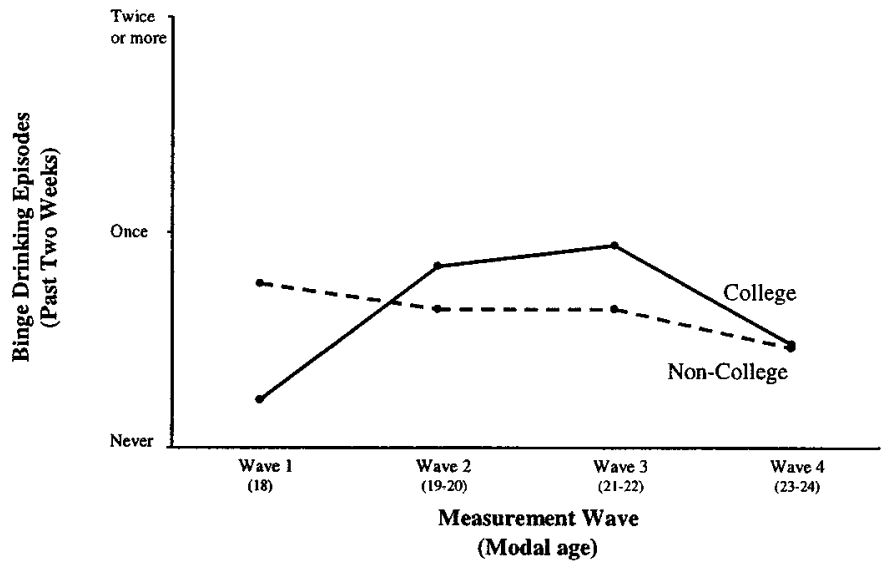

Fig. 1. Mean score for 5 or more drinks in a row in the past 2 weeks by 4-year college student status. Note: Based on Monitoring the Future national panel data, senior year cohorts 1975-1991 (weighted N 16,200) based on (O'Malley and Johnston, in press; Schulenberg and Maggs, in press).

In this symposium, we examined the problem of college drinking from a developmental perspective, presenting and integrating findings from four longitudinal studies that involved nationally representative samples and single university samples. Presentations considered the meaning, functions, and consequences of the use of alcohol in relation to students' changing lives, and focused on differential patterns of change. In addition to using longitudinal data, cross-cutting themes included the meaning and advantages of a developmental perspective, distinguishing between normative and psychopathological patterns, gender differences, and implications for developmental interventions. Our primary goal was to better understand what motivates and inhibits risky drinking from a developmental perspective, 
and to promote a developmental perspective in future research, prevention strategies, and clinical interventions.

Long introduced the topic, noting that college drinking is one of the most significant and complex public health problems today. Alcohol use (much of it illegal underage drinking) is tightly woven into the social fabric of college life, bringing with it enormous social, economic, and personal consequences for some of our country's best and brightest young people and their families. From a scientific perspective, the issue has been particularly frustrating because of the lack of conclusive findings about effective solutions. Despite the large sums of money dedicated to prevention and intervention programs, few programs have shown any significant results, and researchers continue to ask the same fundamental questions year after year. One promising way to frame the issue of college drinking is to view it from a developmental perspective, an approach that can help us understand what motivates and inhibits risky drinking among college students, and what types of interventions might be most appropriate. It is noteworthy that the presenters and discussant in this session are participants in a comprehensive college drinking project sponsored by the NIAAA. This special subcommittee of the NIAAA National Advisory Council consists of researchers, college presidents, and students and is analyzing the current state of the research on this issue. A final report will be issued early in 2001.

\section{"I'M NOT A DRUNK, JUST A COLLEGE STUDENT": BINGE DRINKING DURING COLLEGE AS A DEVELOPMENTAL DISTURBANCE}

\section{John Schulenberg}

Drawing partly from Anna Freud's (1958) notion that adolescence is a necessary perturbation in the life cycle, Schulenberg introduced the concept of "developmental disturbance" to reflect developmentally limited deviance that is statistically normative, culturally sanctioned, and time prescribed. More specifically, the three conditions of a developmental disturbance model include: (a) a timelimited instability of individual differences; (b) difficulty in predicting in advance one's behavior during the developmental disturbance period; and (c) difficulty in predicting from one's behavior during the developmental disturbance period to future functioning and adjustment.

The purpose of this study was to determine the extent to which college binge (or heavy episodic) drinking reflected a developmental disturbance model, using national panel data $(n=16,200)$ from the Monitoring the Future project (Johnston et al., 2000). First, in considering the total sample and college/noncollege subgroups, the stability of individual differences in binge drinking (5 or more drinks in a row), cigarette use, and marijuana use was examined across 2-year segments from age 18 (when respondents were seniors in high school) to 26. Consistent with the first condition of a developmental disturbance model, it was found that binge drinking was less stable than the other substances between the ages of 18 and 24, especially for college students.

In focusing only on full-time 4-year college students who were nonbinge drinkers in high school and then diverged in their binge drinking during college (i.e., rare binge drinkers, "fling" binge drinkers-those who escalate and then decrease during the course of a college career-and increased binge drinkers; see Schulenberg et al., 1996), logistic regression and MANOVA analyses were conducted to attempt to predict divergences and to relate college drinking to adjustment at age 30 . Consistent with the second condition of a developmental disturbance model, the attempt to predict subsequent divergences in the binge drinking trajectories in advance as a function of age 18 psychosocial characteristics proved generally unsuccessful (especially between the fling and increased trajectory groups). Finally, at age 30, the fling and rare groups were found to be indistinguishable in terms of functioning and adjustment (which is consistent with the third condition of a developmental disturbance model), whereas the increased group was clearly experiencing adjustment difficulties.

Overall, findings support the utility of viewing college drinking as a developmental disturbance, at least for a sizable portion of the population. Escalation and decline in binge drinking during college are only modestly predictable in advance, and adulthood outcomes depend more on the course than the peak level of binge drinking during college.

\section{COURSE OF ALCOHOL USE DISORDERS DURING COLLEGE}

\section{Kenneth J. Sher and Heather J. Gotham}

Using data from their ongoing, high-risk, prospective study of young adults who were first assessed as college freshmen, Sher and Gotham, 1999 sought to identify variables measured at baseline or over time (dynamic predictors) that predict the development of an alcohol use disorder (AUD) and/or distinguish between chronic and recovering courses of AUDs across 7 years that encompassed five waves of data collection. Individuals were classified as "Chronics" $(n=29)$ if they met diagnostic criteria for an AUD at all 5 waves; "Remitters" $(n=33)$ if they met diagnostic criteria for an AUD at baseline (Year 1) and at least one other time during the first 4 years of the study (Years 2, 3, or 4), did not meet criteria for an AUD at Year 7, and did not report any past year DSM-III (1980) symptoms of alcohol abuse or dependence at Year 7; and "NonDiagnosers" ( $n=274)$ if they did not meet diagnostic criteria for an AUD at any of the five waves. Subjects with all other diagnostic patterns $(n=115)$ were excluded. Most of these were subjects who diagnosed one to four times over the course of the study but did not meet criteria for the remission category either because of failure to diagnose at baseline or because of diagnosis at year $7(n=106)$. The 
other nine subjects were excluded because although they met criteria for remission, they had subthreshold symptomatology at year 7 .

A wide range of baseline variables was related to an early-onset AUD, however, only motives for drinking and antisociality were related to chronicity of an AUD (see also Sher et al., 1999). With respect to dynamic prediction, we hypothesized six different trajectories of covariates of course and found evidence for five of them: (1) stable vulnerability indicators that distinguish courses in their mean level but did not change over the course of the study (e.g., antisociality), (2) course trackers that covaried over time with the presence or absence of diagnosis (e.g., peer involvement) (3) developmentally specific predictors that predicted course at certain ages but not at others (e.g., alcohol expectancies for performance enhancement), (4) developmental lag indicators that change normatively over the course of developmental but show a delayed change in affected individuals (e.g., generalized distress), and (5) stage-referenced variables whose prognostic significance changed as a function of stage of disorder (e.g., drinking restraint strategies).

There was considerable variability in course (i.e., trajectories) of AUDs, and even greater variability in the trajectories of the covariates of these trajectories (i.e., dynamic predictors). The power of a variable as a marker for AUDs depends on the course of the AUD and the timing of the measurement of the marker. This variability offers clues to the functional relation of covariates to underlying disorders and to the developmental boundary conditions under which it serves to operate. Identifying such patterns is a first step toward understanding the etiologic or consequential role of a diagnosis-related variable. The primary message from these findings is that alcohol use disorders are clearly embedded within a strong developmental context (Sher and Gotham, 1999).

HOW DO STUDENTS EXPERIENCE ALCOHOL AND ITS EFFECTS? POSITIVE VERSUS NEGATIVE EXPECTANCIES AND CONSEQUENCES

\section{Jennifer L. Maggs}

Maggs (1997) reported preliminary findings from the University Life Transitions (ULTRA) Project Telephone Diary Study, which followed college students longitudinally from orientation through the first year of college using an intensive repeated measures design. Based on a developmental perspective and alcohol expectancy theory, the ULTRA Project examines what students learn through naturally occurring experience with alcohol. Questionnaire data collected at orientation served as baseline between-person predictors of within-person fluctuations in alcohol expectancies, consumption, and consequences as assessed in 10 weekly telephone interviews. Specifically, the roles played by positive versus negative expectancies and consequences were contrasted, with the aim of better understanding the experience of and motivations for alcohol use (Maggs, 1997). Based on theory and past research, positive expectancies and consequences were hypothesized to be more salient predictors of use than negative expectancies and consequences.

Results showed that, on average, males drank more drinks and on more days per week than females, but there was no gender difference in the number of binge days per week (binges were defined as $4 / 5$ drinks for females/males). Two-level longitudinal hierarchical linear models assessed: (a) within-person across-time covariation of binge drinking with experienced positive and negative consequences, and (b) prospective short-term changes in expectancies and plans to binge drink. These two-level models nested occasions of measurement (10 weeks of data per person) within participants, yielding over 1925 level 1 cases (personweeks) across the 201 level 2 units (people). Prospective models examined whether expectancies and use were higher (or lower) after weeks where more (or less) alcohol consequences were experienced. Between-persons, students who drank more heavily experienced more positive and negative consequences (in Fun/Social, Relax, Image, Physical/Behavioral, and Driving-related domains). Similarly, within-persons, on weeks students drank more, they experienced more positive and negative consequences, compared to weeks they drank less. At all levels of drinking, however, positive consequences were more frequently experienced. As hypothesized, positive expectancies accounted for larger unique proportions of variance in alcohol use/binge drinking than negative expectancies in both between- and within-person comparisons. In prospective models, when students had experienced more positive alcohol effects the week prior, they consumed more alcohol the following week. However, the experience of negative alcohol effects (though relatively frequent) did not predict reduced (binge) drinking the next week.

Describing and explaining within-person fluctuations and covariation is essential to understanding alcohol use behaviors from the subjective perspective of the individual drinker. These results suggest that they way in which college students experience alcohol and its effects is driven to a great extent by positive expectancies and consequences.

BRIEF INTERVENTION IN THE CONTEXT OF DEVELOPMENTAL TRENDS IN COLLEGE DRINKING

\section{John S. Baer, G. Alan Marlatt, and Daniel R. Kivlahan}

Building on the consistent finding that significant harms are related to heavy episodic drinking (Wechsler et al., 1994), Baer et al. (in press) sought to understand prevention effects in the context of quite different patterns of drinking over time among college students. In their model of indicated prevention, personalized individual feedback and brief motivational and nonconfrontational interviews are conducted with high-risk college students (defined by their heavy drinking during high school) (Marlatt et al., 
1998). High-risk students complete an assessment of their drinking patterns and associated psychological factors (alcohol expectancies, other psychological symptoms, family history of alcohol problems, conduct problems) during their freshman year. Personalized feedback is provided 2-3 months later in the context of a private, one-on-one motivational interview. The interview is client-centered in its tone, but nevertheless seeks to highlight and explore discrepancies between current behavior and plans, goals, and aspirations. Each participant is also given a one-page list of tips for reducing risks associated with drinking. The intervention has been evaluated with a randomized clinical trial with 4-year follow-up. Details of the intervention and research design can be found in other publications (Baer et al., in press; Marlatt et al., 1998).

Assessments 2 and 4 years after baseline assessment reveal that, compared to high risk students in a control condition, those students who received the preventive intervention report reduced rates of problems (Baer et al., in press; Marlatt et al., 1998). At both the 2-year (Roberts et al., 2000) and the 4-year assessments (Baer et al., in press), a risk cut-score analysis was completed to examine individual change trajectories that are masked by analysis of average trends (see Roberts et al., 2000 for details of this method). At the 4-year assessment, the individual risk cutscore analysis categorized many high risk individuals as reducing drinking problems over time (42\%) (and leaving risk status by the end of college), many other high-risk students as stable with regard to risk status (47\%), compared to a much smaller group of individuals (11\%) who report worsening of problems and risk over time. Rates of categorization into different trajectories were compared across prevention and control conditions in the longitudinal study. The prevention program appears effective both by making trajectories of reductions in drinking problems over time more common, as well as by making trajectories of increasing drinking problems over time less common.

This analysis of developmental patterns in heavy drinking over several years during college revealed that drinking reductions were most common for high-risk students. Yet, within an average decline in drinking there were multiple developmental paths; a minority worsened. Brief interventions may have different effects for different individualsprevention might accelerate or support processes associated with risk reduction or maturation, and might dampen processes that support risk taking.

\section{DISCUSSION}

Zucker commented on cross-cutting themes and offered critiques of each study. The distinctions among these four longitudinal studies of college students are noteworthy. Schulenberg et al. (in press) used multi-cohort national panel data with biennial measurement occasions and focused on alcohol (and other substance) use. Sher and Gotham's (1999) study involved a high risk (children of alcohol- ics) sample with annual measurement focusing on diagnosable alcohol use disorders. The study by Maggs (1997) involved weekly assessment of incoming first-year students' alcohol use, expectancies, and consequences. The project by Baer et al. (in press) involved 4-year follow-up assessments of a randomized clinical trial of a brief motivational intervention conducted with "high risk" freshmen; they focused on alcohol use and drinking problems. Given these variations in methods, samples, and strategies, the common themes in the findings and implications are all the more important.

Clearly, there is evidence for the provocative idea that some increases in binge (or heavy episodic) drinking during college are part of a life stage-specific syndrome that serves some positive developmental functions along with negative ones. As a group, these studies show convincingly that even dangerous levels of drinking and related symptomatology during the college years do not always indicate a long-term problem with alcohol use. Equally important, as Schulenberg et al. (in press) shows in particular, such high levels of drinking and problems with drinking during college are not necessary predictable in advance, nor are they predictive of future psychosocial difficulties (consistent with the developmental disturbance notion). This provides a strong argument for the necessity of a developmental perspective, and also illustrates its clear advantages.

The focus on college students was dictated by the topic of the symposium, but it also deserves some comment in its own right. The generally socially effective nature of the college population makes the findings interesting not only for what they have to say about college students, but also what they have to say about this life period more generally. This is especially so with the two high risk studies (Sher and Gotham, 1999; Baer et al., in press) because these studies will tell us how clinical symptomatology and alcoholic diagnoses can overlay on an ostensibly socially competent population. But focusing only on college students to the exclusion of their noncollege peers gives us only half the picture. Furthermore, separating out the experience of college from the full life cycle can be problematic. Schulenberg et al. (2000) and Maggs (1997) each provided some "before data" (Schulenberg's data were from the senior year in high school and Maggs' data were from the summer before college), but one would ideally want developmentally upstream data from substantially earlier in adolescence or even childhood. Otherwise, conclusions about stability and instability during the transition into college may be misleading, insofar as the college indicators may be simple proxy measures for processes already in place, that are continuing to play out. In the opposite developmental direction, all four studies will become even more compelling as they reach further into adulthood, and it will be important to connect postcollege role changes into the data. Dynamic predictors, as Sher and Gotham (1999) illustrate in their study, should be incorporated in future efforts. The more intensive micro-level approach of Maggs 
(1997) has many advantages to studying pivotal transitions, although there clearly is the continued need for the longerterm approaches illustrated in the other three studies.

In regard to predictors and correlates of changes in alcohol use and problems with drinking, there were some expected findings and some surprises. In both the Schulenberg et al. (in press) and the Sher and Gotham (1999) studies, it is clear that many of the so called risk factors in the field are perhaps better thought of as "cotravelers" with alcohol use and problems with drinking (e.g., see Schulenberg et al., in press). In both of these studies, behavioral undercontrol symptomatology, reflective perhaps of an antisocial symptom substrate (cf., Zucker, in press), was important in separating experimental alcohol use from more long-term problem alcohol use. In both the Baer et al. (in press) study and the Maggs (1997) study, symptomatology and diagnosis are only loosely tied to consumption, a finding that occasionally appears in the literature. One wonders the extent to which this is emblematic of college drinking, youthful drinking, or drinking across the lifespan. In the Maggs study, we have a finding that is counter-intuitive and potentially very important. She found that after weeks when students had positive experiences with drinking, they drank more the following week. But when they experienced negative consequences, this had no apparent effect on their future avoidance of such experiences. Perhaps this is related to feelings of personal invulnerability. This significant finding deserves further exploration.

Perhaps one of the most clinically significant implications from this group of papers is that diagnostic criteria of alcohol abuse and dependence ought to incorporate some index of developmental course of use and symptomatology. Finally, in building on the success of the brief motivational intervention with college students indicated in the Baer et al. (in press) study, designers of intervention programming ought to be working toward matching interventions with the expected trajectory of alcohol use and abuse of their students.

\section{REFERENCES}

American Psychiatric Association (1980) Diagnostic and Statistical Manual of Mental Disorders: DSM-III 3rd ed. American Psychiatric Association, Washington, DC.
Baer JS, Kivlahan DK, Blume A W, McKnight P, Marlatt G A (2000) Brief intervention for heavy drinking college students: Four-year follow-up and natural history. Am J Public Health, in press.

Freud A (1958) Adolescence. Psychoanal Study Child 12:255-278.

Johnston LD, O'Malley PM, Bachman JG (2000) Monitoring the future national survey results on drug use, 1975-1999. Volume I: Secondary school students. NIH Publication No. 00-4802. National Institute on Drug Abuse. Rockville, MD.

Maggs JL (1997) Alcohol use and binge drinking as goal-directed action during the transition to university, in Health Risks and Developmental Transitions During Adolescence (Schulenberg J, Maggs JL, Hurrelmann, K eds), pp. 345-371. Cambridge University Press, New York.

Marlatt GA, Baer JS, Kivlahan DR, Dimeff LA, Larimer ME, Quigley LA, Somers JM, Williams E (1998) Screening and brief intervention for high-risk college student drinkers: Results from a two-year follow-up assessment. J Consult Clin Psychol 66:604-615.

O'Malley PM, Johnston LD (2000) Epidemiology of alcohol use among college students. Chapter in upcoming NIAAA monograph on college drinking, in press.

Roberts LJ, Neal DJ, Kivlahan DR, Baer JS, Marlatt GA (2000) Individual drinking changes following a brief intervention among college students: Clinical significance in an indicated preventive context. J Consult Clin Psychol 68:500-505.

Schulenberg J, Maggs JL (2000) A developmental perspective on alcohol use and heavy drinking during adolescence and the transition to young adulthood. Chapter in upcoming NIAAA monograph on college drinking., in press.

Schulenberg J, Maggs JL, Steinman K, Zucker RA (2000) Development matters: Taking the long view on substance abuse etiology and intervention during adolescence, in Adolescents, Alcohol, and Substance Abuse: Reaching Teens Through Brief Intervention (Monti PM, Colby SM, O'Leary, TA ed). Guilford Press, New York, in press.

Schulenberg J, O'Malley PM, Bachman JG, Wadsworth KN, Johnston LD (1996) Getting drunk and growing up: Trajectories of frequent binge drinking during the transition to young adulthood. J Stud Alcohol 57:289-304.

Sher KJ, Gotham H (1999) Pathological alcohol involvement: A developmental disorder of young adulthood. Dev Psychopathol 11:933-956.

Sher KJ, Trull TJ, Bartholow B, Vieth A (1999) Personality and alcoholism: Issues, methods, and etiological processes, in Psychological Theories of Drinking and Alcoholism (K Leonard and H Blane eds) 2nd ed, pp. 55-105. Plenum, New York

Wechsler H, Davenport A, Dowdall G, Moeykens B, Castillo S (1994) Health and behavioral consequences of binge drinking in college: A national survey of students at 140 campuses. JAMA 272:16721677.

Zucker RA (2000) Alcohol involvement over the life course, in National Institute on Alcohol Abuse and Alcoholism Tenth Special Report to the US Congress on Alcohol Abuse and Alcoholism, pp.28-53. National Institute on Alcohol Abuse and Alcoholism, Rockville, MD. 